\title{
La lucha por la libertad durante tiempo de crisis
}

\author{
Lauren DeVeau \\ Universidad Antonio Ruiz de Montoya
}

"La frontera está cerrada hasta un nuevo aviso", dijo el presidente Vizcarra. En todos los posibles escenarios que contemplé antes de mudarme al Perú, jamás imaginé el no poder regresar a mi país de origen como posibilidad. Mientras intentaba absorber esta nueva realidad, pensé en la gran cantidad de extranjeros, migrantes e inmigrantes que han dejado sus tierras por temas de guerra, violencia o pobreza, algunos sabiendo que no iban a regresar jamás. Las crisis nos dejan sin muchas opciones, nos limitan y nos obligan a escoger entre necesidades básicas como la salud, la alimentación o la economía. Hay muchos países y poblaciones quienes, desafortunadamente por sistemas injustos, han sido obligados a vivir en crisis. Sus recursos y derechos han sido limitados por décadas y siglos, pero para otros, la COVID-19 representa la primera vez en la que han sentido limitaciones que interrumpen su forma de vivir no solo para su propio bienestar, sino también para el bien común. A diferencia de otras crisis, con la COVID-19 no se puede determinar cómo uno va a ser afectado. Esta crisis no es una guerra civil en otro país o discriminación de otra raíz, es una enfermedad que, de una u otra forma, afecta a todos. Es por ello que la COVID-19 nos brinda la oportunidad de examinar la calidad de nuestra vida colectiva y aprender la importancia de limitarnos a nivel individual para brindar mayor libertad a nivel social.

¿Qué es libertad, cómo la medimos? En muchos países del mundo, la libertad es un derecho humano, sin embargo, el nivel de libertad varía según el contexto. El Índice de la Libertad Humana incluye 76 indicadores para medirla, entre ellos, seguridad, expresión, información, relaciones, religión, asamblea, movimiento, regulación de labor, entre otros. La medición se realiza en escala de 0 - 10 para mostrar a los países más libres. En el año 2019, Finlandia y Alemania empataron en el primer lugar, y en el último lugar estaba Siria. Como región, ganó América del Norte. Perú recibió 7.61 en libertad personal y 7.49 en libertad económica. 
El 2020 nos reta con más preguntas acerca del derecho de la libertad. En este ańo, hemos visto tantas protestas en el nombre de la calidad de vida. Según el World Wide Politics Review, entre marzo y octubre de este año 2020, hubo más de 30 protestas sobre las restricciones de coronavirus en varios rincones del mundo: desde Alemania, Estados Unidos, Nigeria y Brasil, la clase élite de centros urbanos y pobres de áreas rurales han reclamado las estrictas medidas tomadas por la COVID-19. Hay otras protestas sobre de las restricciones en trabajo como en Malawi en las que comerciantes protestaron que iban a morir de hambre antes que de COVID-19. En México y Sudáfrica, trabajadores de hoteles y turismo protestaban sobre las restricciones de aforos y la falta de trabajo. La pandemia no solo nos ha encerrado en nuestras casas, sino que también nos pide preguntar qué es más importante: ¿la economía, la alimentación, la educación o la salud física y mental?

No hay respuestas fáciles. No puede ser igual para cada país, pero hemos visto respuestas que no funcionan; la más evidente es la decisión de no usar mascarillas y aún más peligroso, la división de la sociedad. He visto esto dentro de mi propio país de origen y mi estado, Michigan. Durante la pandemia, Trump ha expresado un odio grande hacia la gobernadora, Gretchen Thitmer, y ha twitteado expresiones como "Liberar Michigan", lo cual incentiva a sus seguidores de invadir la capital con armas, planear el secuestro y posible asesinato de la misma gobernadora.

Al mismo tiempo, hemos visto protestas sociales contra problemas que nos han afectado por siglos, como el racismo y la corrupción. Las protestas de Black Lives Matter se realizaron en EE. UU., Japón, Alemania, Holanda, Inglaterra, Colombia, Polonia, Brasil y Francia. El movimiento de Black Lives Matter ha tenido tanto éxito no solo por la participación de la gran cantidad de comunidades afroamericanas, sino también por la presencia de las personas blancas. Se ha dejado de ver el racismo como un problema solo de los afroamericanos y/o los latinos, y se ha visto como un problema humano. Es así como cuando dejamos de separarnos del problema y nos involucramos o aceptamos nuestro rol dentro de ello, esto nos permite ser parte de la solución. Hemos sido testigos de la muerte de ciudadanos por la excesiva violencia de algunos policías, lo cual ha encendido una rabia y un amor tan profundo que ha 
producido un espíritu de lucha por el bien común, donde se olvidan las libertades individuales y se busca la justicia social y un cambio sostenible.

Sin embargo, ¿cómo podemos generar un mayor interés en el bien común en vez de solo en el beneficio propio? Tenemos que tomar el tiempo de crear los espacios para encontrarnos. Es importante salir de nuestras zonas de confort y conocer personas de diferentes raíces, clase social, cultura y experiencia de vida. Aunque no hemos podido salir del país, la tecnología nos brinda la oportunidad de seguir conectados. Este semestre he podido ser testigo de las conversaciones semanales de alumnos de la UARM y alumnos de Xavier University a través de COIL (Collaborative Online International Learning). En la última sesión de encuentros, la directora de educación internacional de Xavier les preguntaba qué es lo que han aprendido de esta experiencia; la respuesta más común fue "que nos hemos convertido en amigos". Entonces, los medios virtuales son una gran herramienta de encuentro, aun en pandemia, ya que hay espacios para hacer voluntariado virtual, para crear un podcast propio y hablar sobre algún problema en común o involucrarse en la política.

La COVID-19 ha menguado miembros de las familia y de la comunidad, y ha reducido oportunidades de empleo; nos ha aislado, pero no nos ha separado permanentemente. Para los que tienen el privilegio de quedarse en casa, podemos preguntarnos cómo podemos aprovechar este espacio y tiempo para no solo asegurar en el futuro que estemos libres de salir a la calle sin mascarilla, pero también ser libres, con menos corrupción, pobreza o cambios climáticos. Terminaremos este año exhaustos. Aunque sabemos que una vacuna vendrá, también somos conscientes de que el fin de esta crisis no es el fin de todas las demás. Mientras sigamos en esta crisis de COVID-19, ¿`ómo podemos combatir otras crisis, como la climática, la de pobreza o la de corrupción? ¿Cómo podemos aprovechar los momentos en casa para leer, conectar vía redes sociales y pensar sobre estas luchas de largo camino? Esto requiere de creatividad y el coraje de repensar e imaginar un mundo más justo y con mayor libertad para todos. A veces, requiere dejar de pensar en nuestro propio bien y tener la perspectiva de ver más allá de este instante y de nosotros mismos. 


\section{Referencias}

Amid the COVID-19 pandemic, protest movements challenge lockdowns worldwide. (2020, October 15). World Politics Review. Analysis of international affairs and global trends. https://www.worldpoliticsreview.com/articles/29137/amid-thecovid-19-pandemic-protest-movements-challenge-lockdownsworldwide

Human freedom index. (2020, March 26). Cato Institute. https:// www.cato.org/human-freedom-index-new 